\title{
Predictive and prognostic impact of preoperative complete blood count based systemic inflammatory markers in testicular cancer
}

\author{
Ersan Arda ${ }^{1}$, Gurkan Arikan ${ }^{1}$, Hakan Akdere ${ }^{1}$, Murat Akgul ${ }^{2}$, Ilkan Yuksel ${ }^{1}$ \\ ${ }^{1}$ Department of Urology, Trakya University School of Medicine, Edirne, Turkey; ${ }^{2}$ Department of Urology, \\ Namik Kemal University School of Medicine, Tekirdăg, Turkey
}

\section{ABSTRACT}

Purpose: To determine the utility of preoperative complete blood count (CBC) based systemic inflammatory markers in the prediction of testicular cancer and its prognosis. Material and Methods: Between 2008-2017 the data of all testicular tumor patients undergoing radical orchiectomy were retrospectively analyzed. Patient baseseline characteristics (age, tumor stage, tumor markers, etc.) and results of routine preoperative blood tests including mean platelet volume (MPV), red cell distribution width (RDW), lymphocyte ratio (LR) and neutrophil ratio (NR) were retrieved. In addition, neutrophil to lymphocyte ratio (NLR) was calculated.

Results: Mean age of the tumor and control group was $36.0 \pm 15$ and $30.50 \pm 11$ years, respectively. Mean RDW, NR and NLR were significantly higher in the tumor group with $p$ values $<0.001$; whereas LR and MPV were significantly higher in the control group ( $<<0.001)$. Receiver Operating Characteristic (ROC) analyses of LR, NR, RDW, MPV, and NLR are shown in Table-3. The cut off values for RDW and NR were found as 13,7 (Area under the curve (AUC): 0.687, sensitivity $=42.2 \%$, specificity $=84.8 \%$ ) and 55.3 (AUC:0.693, sensitivity 72.2\%, specificity 62\%), respectively. Area under the curve for NLR in tumor group was 0.711 , with a threshold value of 1.78 and sensitivity $=81.8 \%$ and specificity $=55.4 \%$ (AUC:0.711/sig<0.001) that together with RDW exhibited the best differential diagnosis potential which could be used as an adjuvant tool in the prediction of testicular tumor and its prognosis.

Conclusion: Several systemic inflammatory markers, which are obtained by routinely performed cost-effective blood tests, could demonstrate incremental predictive and prognostic information adjuvant to preoperativly achieved testiscular tumor markers.

\section{ARTICLE INFO}

\section{Ersan Arda}

http://orcid.org/0000-0002-5430-6561

\section{Keywords:}

Testicular Neoplasms;

Neutrophils; Lymphocytes

Int Braz J Urol. 2020; 46: 216-23

Submitted for publication:

November 30, 2018

Accepted after revision:

July 24,2019

Published as Ahead of Print:

September 10, 2019

\section{INTRODUCTION}

Testicular cancer is the most common malignancy in men between the ages of 20-40 and constitutes about $1-1.5 \%$ of all cancers. Mainly, it can be classified as germ cell, sex cord-gonadal stromal and secondary testicular tumors (1). Clinical admission, in daily urology practice, is usually due to painless testicular mass, while serum tumor markers (human chorionic gonadotropin (HCG), alpha-fetoprotein (AFP) and lactate dehydrogenase (LDH) and scrotal ultrasonography are used for definitive diagnosis (2). 
Studies investigating the relationship of inflammation and cancer, by revealing different mechanisms of influence, are increasing in recent years. It has been reported that tumor cells are triggering cancer-related inflammation, and increasing tumor promoting effect, by secreting chemokines, cytokines and prostaglandins (3). Particularly, in various urinary tract malignancies such as renal cell carcinoma (RCC), bladder cancer and prostate cancer, it has been claimed that cancer-related inflammation plays an important role in disease progression and prognosis (4). In addition, a recent study showed that chronic inflammatory processes such as orchitis-epididymorchitis can influence the formation of testicular malignancy (5). Therefore, taken into account the role of inflammation in tumor biology, using inflammatory markers such as neutrophil ratio (NR), lymphocyte ratio (LR) and/or neutrophil to lymphocyte ratio (NLR) in predicting the occurence and prognosis of the disease, is of great importance (6). Among these markers, it has been suggested that, especially NLR reflects immune response and can be used as a prognostic marker, in many urologic malignancies (7). Nowadays, as a result of previously accomplished studies, the European Urological Association approved NLR as a prognostic parameter for RCC (8).

Even though inflammatory processes comprise a more important role in testicular tissue than other urinary tract organs, there are only a few studies showing the relationship between inflammatory markers and testicular cancer.

Based on the above mentioned hypothesis, we aimed to determine the utility of preoperative complete blood count (CBC) based systemic inflammatory markers in the prediction of testicular cancer and its prognosis.

\section{MATERIAL AND METHODS}

Between 2008-2017, the data of all testicular tumor patients, who underwent radical orchiectomy in two University Hospitals in the Region of Trakya (Turkey) were retrospectively examined. Histopathologically proven testicular germ cell tumor patients of stage pT1-T4 including any regional lymph node positivity without distant organ metastasis, and healthy unoperated grade 1 varicocele individuals with peripheral blood count results, were included in the study and defined as tumor and control group, respectively.

Patient baseline characteristics (age, tumor stage, etc.) and routine preoperative blood test results were retrieved from both hospitals electronic data base. Biochemical analyses included testicular tumor markers (AFP, HCG, LDH) and CBC-based systemic inflammatory markers such as mean platelet volume (MPV), red cell distribution width (RDW), LR and NR. Additionally to the extracted CBC based markers, NLR was calculated to compare between the groups.

The following exclusion criterias for both groups were used: i) men with a secondary malignancy: ii) presence of another active infection: iii) disease causing increased inflammatory response (e.g. familial mediterranean fever): iv) hematologic diseases affecting blood count: and/or v) receiving chemotherapy, meanwhile.

Definition of cancer specific survival (CSS) was the time period (in months) involving time of surgery to cancer related death. Postoperative follow-up of testicular tumor patients in both clinics were routinely performed according to the EAU guideline protocol (9). Informed consents were taken and institutional review board was approved by the hospital ethics committee.

\section{Statistical analysis}

Statistical analyses were performed by $\mathrm{R}$ version 3.5.3 (2019-03-11). Continuous variables were expressed as means (standard deviation (SD)) or median (interquartile range (IQR)) where appropriate, categorical variables were expressed as frequencies and percentages. Variables were compared for statistical significance between groups by Student t-test or Mann Whitney U test. The assocaiton between categorical variables was tested using Fisher's exact test. Kaplan Meier analysis was used to correlate NLR with CSS. Receiver operating characteristic (ROC) curve analyses were performed to assess the discriminative ability of the biomarkers for testicular cancer. The cut-off points for biomarkers were determined by a 
criterion based on Youden's Index defined as Y $\mathrm{I}(\mathrm{c})=\operatorname{maxc}(\mathrm{Se}(\mathrm{c})+\mathrm{Sp}(\mathrm{c})-1)$ and the corresponding specificity-sensitivity levels were provided.

For all analyses, the $p$ value of $p<0.05$ was considered statistically significant.

\section{RESULTS}

After determining inclusion/exclusion criterias, a total of 182 patients were included in the study and divided into two groups, as tumor and control groups, with 90 and 92 patients each, respectively. Descriptive properties and their distribution with respect to groups are summarized in Table- 1 .

Mean age of the tumor and control groups was $36.0 \pm 15$ and $30.50 \pm 11$ years, respectively. Pathological subtypes consisted of 90 germ cell tumors including 42 seminomas (46.6\%), 48 non-seminoma (53.4\%), with a mean follow-up period of 39.83 months. According to the TNM classification, patients comprised of $56(62.2 \%)$ pT1, 28 (31.1\%) pT2, 4 (4.4\%) pT3 and 2 (2.2\%) pT4 patients (Table-2). Mean RDW, NR and NLR were significantly higher in the tumor group with $p$ values $<0.001$, whereas LR and MPV were significantly higher in the control group ( $p$ <0.001). During follow-up, postoperative 68 patients of the tumor group got an additional treatment such as chemotherapy $(n=62)$, radiotherapy $(n=3)$ or chemoradiotherapy $(n=3)$.

Receiver Operating Characteristic (ROC) analyses of LR, NR, RDW, MPV and NLR are shown in Table-3 and Figure-1. The cut off values for RDW and NR were found as 13.7 (Area under the curve (AUC): 0.687, sensitivity $=42.2 \%$, specificity $=84.8 \%$ ) and 55.3 (AUC: 0.693, sensitivity $=72.2 \%$, specificity $=62 \%$ ), respectively. Area under the curve for NLR in tumor group was 0.711 , with a threshold value of 1.78 and sensitivity $=81.8 \%$ and specificity $=55.4 \%$ (AUC: $0.711 / \mathrm{sig}<0.001$ ) that together with RDW exhibited the best differential diagnosis potential which could be used as an adjuvant tool in the prediction of testicular tumor and its prognosis (Table-3).

Distribution of descriptive properties and comparison of clinical parameters between the patients with respect to NLR cut-off values

Table 1 - Descriptive statistics and comparisons of CBC based parameters with respect to groups.

\begin{tabular}{|c|c|c|c|}
\hline Variables & $\begin{array}{l}\text { Tumor group } \\
\qquad(n=90)\end{array}$ & $\begin{array}{l}\text { Control group } \\
\qquad(\mathrm{n}=92)\end{array}$ & $P$ value \\
\hline Age (years) & $\begin{array}{c}36(15) \\
\min : 20 ; \max : 76\end{array}$ & $\begin{array}{c}30.50(11) \\
\text { min:16; max:54 }\end{array}$ & $<0.001$ \\
\hline LR $(\%)$ & $\begin{array}{c}26.15(14.23) \\
\min : 5.5 ; \max : 80\end{array}$ & $\begin{array}{c}33.90(11.78) \\
\min : 11.10 ; \max : 13.30\end{array}$ & $<0.001$ \\
\hline NR (\%) & $\begin{array}{c}63.20(13.10) \\
\min : 6 ; \text { max:87.2 }\end{array}$ & $\begin{array}{c}53.95 \text { (13.65) } \\
\text { min:33.6; } \max : 81.9\end{array}$ & $<0.001$ \\
\hline NLR (\%) & $\begin{array}{c}2.37(2.02) \\
\min : 0.33 ; \max : 15.85\end{array}$ & $\begin{array}{c}1.6(1.05) \\
\min : 0.58 ; \max : 7.38\end{array}$ & $<0.001$ \\
\hline $\operatorname{MPV}\left(10^{3} / \mathrm{uL}\right)^{*}$ & $\begin{array}{c}8.35(1.17) \\
\min : 6.02 ; \max : 11.4\end{array}$ & $\begin{array}{c}9.09(2.33) \\
\min : 6.10 ; \max : 13.3\end{array}$ & $<0.001$ \\
\hline RDW (103/uL) & $\begin{array}{c}13.50(1.47) \\
\min : 11.50 ; \max : 25.80\end{array}$ & $\begin{array}{c}12.9(0.85) \\
\min : 11.6 ; \max : 17\end{array}$ & $<0.001$ \\
\hline
\end{tabular}

LR = Lymphocyte ratio; $\mathbf{M P V}=$ Mean platelet volume; $\mathbf{C B C}=$ Complete blood count; $\mathbf{N L R}=$ Neutrophil/Lymphocyte ratio; $\mathbf{R D W}=$ Red cell distribution width; $\mathbf{N R}=$ Neutrophil ratio

*: The variables with asterisk are described by mean (standard deviation), and the corresponding $p$ value is based on t-test, otherwise the variables are described by median (interquartile range) and the corresponding $p$ value is based on Mann Whitney $\mathrm{U}$ test. 
Table 2 - Tumor Classification and Pathological Stage

\begin{tabular}{|c|c|c|c|}
\hline Subtypes of Tumor & & $\begin{array}{l}\text { Number } \\
\text { (n) }\end{array}$ & $\begin{array}{l}\text { Percentage } \\
(\%)\end{array}$ \\
\hline \multirow{18}{*}{$\begin{array}{l}\text { GERM CELL TUMORS } \\
(\mathrm{n}=90)\end{array}$} & Seminoma & & \\
\hline & $\mathrm{pT} 1$ & 26 & 28.9 \\
\hline & рT2 & 15 & 16.7 \\
\hline & рT3 & - & - \\
\hline & pT4 & 1 & 1.1 \\
\hline & Mix germ cell & & \\
\hline & pT1 & 25 & 27.8 \\
\hline & pT2 & 13 & 14.4 \\
\hline & рT3 & 3 & 3.3 \\
\hline & pT4 & 1 & 1.1 \\
\hline & Yolc sac & & \\
\hline & pT1 & 2 & 2.2 \\
\hline & Immature teratoma & & \\
\hline & pT1 & 2 & 2.2 \\
\hline & Mature teratoma & & \\
\hline & pT3 & 1 & 1.1 \\
\hline & Germ cell neoplasy & & \\
\hline & $\mathrm{pT} 1$ & 1 & 1.1 \\
\hline
\end{tabular}

Table 3 - Optimal cut-off values and ROC analyses for LR, NR, RDW, MPV and NLR.

\begin{tabular}{lcccccc}
\hline Variables & AUC & Cut-off & Sensitivity & Specificity & PPV & NPV \\
\hline Preop RDW & 0.687 & $>13.7$ & $42.2 \%$ & $84.8 \%$ & $73.1 \%$ & $60 \%$ \\
Preop NLR & 0.711 & $>1.78$ & $81.8 \%$ & $55.4 \%$ & $64.3 \%$ & $76.1 \%$ \\
Preop NR & 0.693 & $>55.3$ & $72.2 \%$ & $62 \%$ & $65 \%$ & $70 \%$ \\
Preop LR & 0.698 & $<28.7$ & $62.2 \%$ & $70 \%$ & $67 \%$ & $65 \%$ \\
Preop MPV & 0.636 & $<33.4$ & $78.9 \%$ & $44.6 \%$ & $58.2 \%$ & $68.3 \%$ \\
\hline
\end{tabular}

RDW = Red cell distribution width; $\mathbf{N R}=$ Neutrophil ratio; $\mathbf{N L R}=$ Neutrophil to Lymphocyte ratio; $\mathbf{M P V}=$ Mean platelet volume; $\mathbf{L R}=$ Lymphocyte ratio; $\mathbf{A U C}=$ Area under the curve; $\mathbf{P P V}=$ Positive Predictive Value; NPV = Negative Predictive Value; $>$ : greater than, $<:$ smaller than

$(<1.78$ and $\geq 1.78)$ are shown in Table-4. Except HCG, NR, LR and NLR no statistically significant difference was found between both groups.

Mean NLR of 42 patients with stage pT1, and 48 patients with stage $\geq \mathrm{pT} 2$, was 3.06 and 3,15 , respectively. Neutrophil to lymphocyte ratio was quantitatively higher in patients with a stage $\geq \mathrm{T} 2$, however no statistically significant difference between both groups was observed $(p=0.107)$. Retroperitoneal lymph node metastases, at the time of disease diagnosis, was revelead in two of 25 patients (8.00\%) with a NLR $<1.78$ and in nine of 65 patients (13.85\%) with a NLR $\geq 1.78$. 
Figure 1 - Optimal cut-off values and ROC analyses for LR, NR, RDW, MPV and NLR.

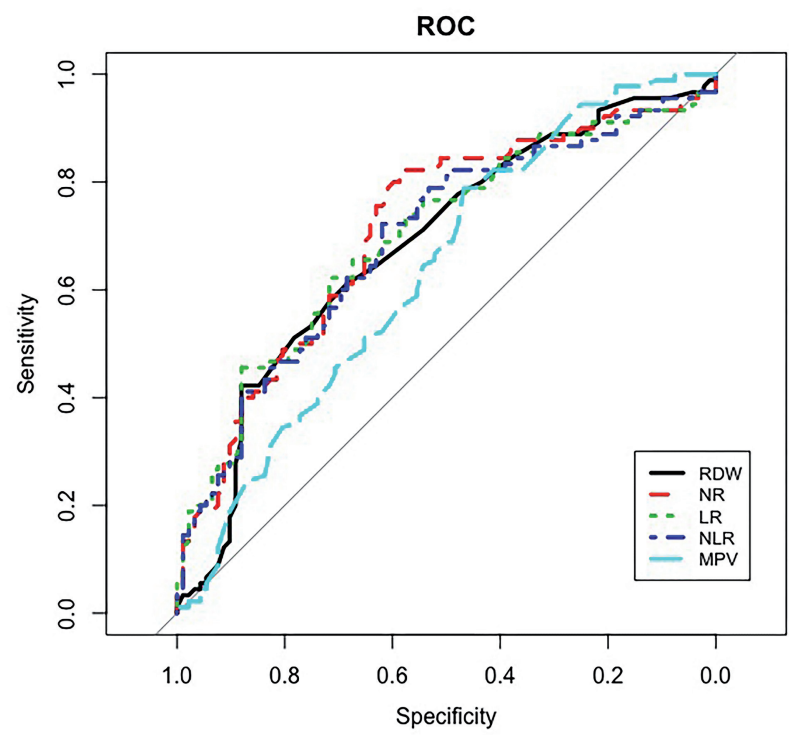

Mean CSS of all patients was calculated as $84.78 \pm 4.89$ months, whereas median CSS was found 96 month showing no difference between the groups according to NLR cut-off value $(\mathrm{p}=0.378)$ (Figure-2) In addition, five year overall survival rates for patients with NLR $<1.78$ and $\geq 1.78$ were found as $54.00 \%$ and $48.00 \%$, respectively.

\section{DISCUSSION}

Immune mechanisms, such as the role of neutrophils as a promoter in tumor formation and the presence of antitumoral activity of lymphocytes have been reported to be associated with malignancies (10). Studies have shown that systemic inflammatory markers, including cytokines, C-reactive protein (CRP), albumin, serum amyloid A and leukocytes, may be independent prognostic factors in cancer patients (11). Recently, in addition to those markers, NLR and platelet lymphocyte ratio (PLR) have been extensively investigated and their relation to the formation and progression of malignancy were reported (10). Especially in urinary system malignancies like prostate, bladder and kidney cancers, the role and efficiency of NLR has been shown in several studies $(6,12-14)$.
Researchers investigating the relationship between tumor size and NLR in patients with RCC, demonstrated that NLR was significantly higher in patients with a tumor size larger than $4 \mathrm{~cm}$ (15). Considering that RCC's larger than $4 \mathrm{~cm}$ are upstaged according to the TNM classification, it was thought that NLR may correlate with tumor stage. Based on this suggestion, the obtained results of our testicular tumor patients revealed a significant correlation between tumor stage and the NLR cut off value, supporting previously accomplished studies $(15,16)$. Apart from this, a study evaluating ovarian mature cystic teratoma patients, it was reported that NLR was significantly higher in patients that showed malignant transformation (7). Interpreting our results, besides the similarity of embriological origin and exposion of frequent inflammatory processes identical to the testes, this finding could contribute to the literature in terms of showing the association of NLR and genitourinary related malignancies.

We sought to describe the potential association between preoperative CBC-based blood count parameters and testicular cancer patients who underwent radical orchiectomy. The major findings of the present study are that: i) RDW, NR and NLR are significantly higher in testicular tumor patients compared to healthy control subjects, and ii) especially NLR and RDW could be used as a predictive and/or prognostic factor showing the highest sensitivity and specificity, respectively.

In a study comparing 36 patients with localized testicular cancer and 36 control subjects, it was shown that NR and NLR were significantly higher in the tumor group, whereas LR was higher in the control group, which was in agreement to our findings (4). However, ROC analysis revealed a significantly lower NLR cut off value and sensitivity compared to our results, which we believe to be caused due to the small sample size of this study.

Jankovich et al. (17), studied 103 testicular germ cell tumor (GCT) patients and evaluated the prevalence of their histopathology, metastatic status and tumor stage according to NLR $<4$ or NLR $\geq 4$. Despite that, NLR cut off value was considera- 
Table 4 - Distribution of descriptive properties and comparison of clinical parameters between the patients with respect to NLR of $<1.78$ and $\geq 1.78$.

\begin{tabular}{|c|c|c|c|}
\hline Variables & $\begin{array}{c}\text { NLR } \\
<1.78(n=25)\end{array}$ & $\begin{array}{c}\text { NLR } \\
\geq 1.78(n=65)\end{array}$ & $P$ value \\
\hline Age (years), Median (IQR) & $36.00(12.00)$ & $36.00(16.00)$ & 0.576 \\
\hline Tumor size $\left(\mathrm{cm}^{3}\right)$, Median (IQR) & $6.00(45.40)$ & $13.50(67.00)$ & 0.313 \\
\hline Follow-up (months), Median (IQR) & $36.00(36.00)$ & $24.00(48.00)$ & 0.282 \\
\hline Stage, $n(\%)$ & & & 0.475 \\
\hline $\mathrm{T} 1$ & $17(68.00 \%)$ & $38(58.46 \%)$ & \\
\hline$n \geq T 2$ & $8(32.00 \%)$ & $27(41.54 \%)$ & \\
\hline \multicolumn{4}{|l|}{ Tumor markers, Median (IQR) } \\
\hline Preop AFP $(\mathrm{U} / \mathrm{mL})$ & $4.50(10.28)$ & $5.10(147.14)$ & 0.385 \\
\hline Preop HCG (mIU/mL) & $1.00(4.65)$ & $5.00(41.00)$ & $0.047^{*}$ \\
\hline Preop LDH (U/L) & $310.00(242.00)$ & $335.00(386.00)$ & 0.859 \\
\hline \multicolumn{4}{|l|}{ CBC based markers, Median (IQR) } \\
\hline Preop NR (\%) & $52.00(11.00)$ & $68.10(11.00)$ & $<0.001^{*}$ \\
\hline Preop LR (\%) & $36.30(6.70)$ & $22.10(10.60)$ & $<0.001^{*}$ \\
\hline Preop NLR (\%) & $1.38(0.42)$ & $3.12(2.27)$ & $<0.001^{*}$ \\
\hline Preop MPW (103/uL) & $8.00(1.90)$ & $8.20(1.60)$ & 0.491 \\
\hline Preop RDW (103/uL) & $13.30(2.10)$ & $13.50(1.20)$ & 0.695 \\
\hline $\begin{array}{l}\text { Lymph node metastasis at the time of diagnosis, } \\
\text { n (\%) }\end{array}$ & $\begin{array}{l}2(8.00 \%) \\
23(92 \%)\end{array}$ & $\begin{array}{l}9(13.85 \%) \\
56(86.15 \%)\end{array}$ & 0.721 \\
\hline $\begin{array}{l}\text { Prognostic factors related to occult metastatic } \\
\text { disease }^{*}, \mathrm{n}(\%)\end{array}$ & $\begin{array}{c}8(32.00 \%) /+17(62.00 \%) \\
/-\end{array}$ & $\begin{array}{c}27(41.54 \%) /+38 \\
(58,36 \%) /-\end{array}$ & 0.475 \\
\hline $\begin{array}{l}\text { CSS, } \mathbf{n}(\%) \\
\text { Survived Ex }\end{array}$ & $\begin{array}{c}19(76.00 \%) \\
6(24.00 \%)\end{array}$ & $\begin{array}{l}48(73.38 \%) \\
17(26.62 \%)\end{array}$ & 1 \\
\hline
\end{tabular}

$\mathbf{A F P}=$ Alfa feto protein; $\mathbf{H C G}=$ Human chorionic gonodotropin; $\mathbf{L D H}=$ Lactate dehidrogenase; $\mathbf{L R}=$ Lymphocyte ratio; $\mathbf{N R}=$ Neutrophil ratio; $\mathbf{M P W}=$ Mean platelet volume; $\mathbf{N L R}=$ Neutrophil/Lymphocyte ratio; RDW = Red cell distribution width.

${ }^{*}$ Rete testis invasion, Lymphovascular invasion

bly higher than ours, no statistically significant difference according to these parameters was observed, which was supported by our findings.

In another study conducted by Bolat et al., patients were divided and compared according to the NLR treshold value of $<3.55$ and $\geq 3.55$, to investigate its potential impact on the prognosis of testicular GCT. Similar to our findings, no significant relation between NLR and tumor stage or prognostic factors related to occult metastasis, like rete testis invasion and/ or lymphovascular invasion, was obtained. However, the average sample size and inclusion of distant organ metastatic patients to such a small group, made the clinical evaluation of their data difficult and query (18). 
Figure 2 - Kaplan-Meier curves used to evaluate the correlation between neutrophil-to lymphocyte ratio and CSS.

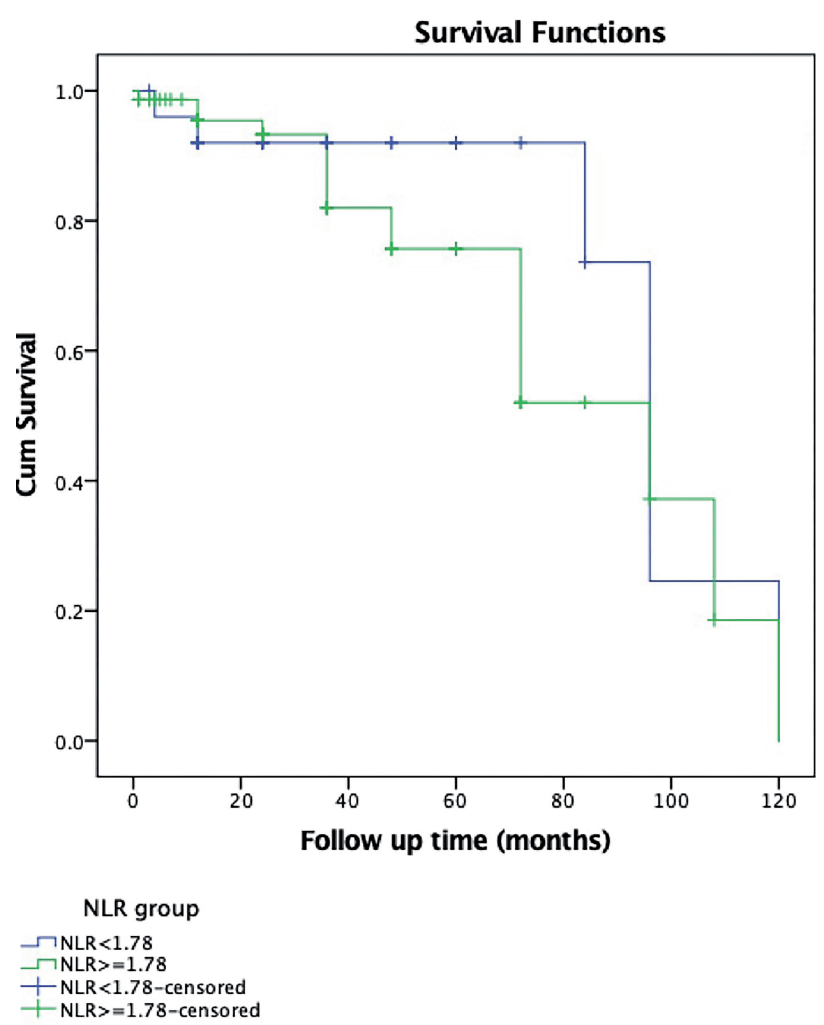

Despite the adequate patient size, the retrospective nature and the inability of comparing extently matched metastatic and non-metastatic patients, according to NLR and other inflammatory markers, are considered the main limitations of the present study. Additionally, due to treatment strategies of testicular masses we could not consider the circadien rhythm of neutrophils and lymphocytes during blood sample collection. Apart from these, it could be interesting to evaluate preoperative to postoperative alterations of NLR and other $\mathrm{CBC}$ based inflammatory parameters after tumor removal and to compare the sensitivity and specificificity against established routine testis tumor markers.

\section{CONCLUSIONS}

Several systemic inflammatory markers, which are obtained by routinely performed cost- -effective blood tests, could demonstrate incremental predictive and prognostic information adjuvant to preoperativly achieved testicular tumor markers. However, further research is needed.

\section{CONFLICT OF INTEREST}

None declared.

\section{REFERENCES}

1. Boccellino M, Vanacore D, Zappavigna S, Cavaliere C, Rossetti S, D'Aniello C, et al. Testicular cancer from diagnosis to epigenetic factors. Oncotarget. 2017;8:104654-63.

2. Smith ZL, Werntz RP, Eggener SE. Testicular Cancer: Epidemiology, Diagnosis, and Management. Med Clin North Am. 2018;102:251-64

3. Mantovani A, Allavena P, Sica A, Balkwill F. Cancer-related inflammation. Nature. 2008;454:436-44.

4. Yuksel $\mathrm{OH}$, Verit $A$, Sahin A, Urkmez A, Uruc F. White blood cell counts and neutrophil to lymphocyte ratio in the diagnosis of testicular cancer: a simple secondary serum tumor marker. Int Braz J Urol. 2016;42:53-9.

5. Kao LT, Lin HC, Chung SD, Huang CY. Association between Testicular Cancer and Epididymoorchitis: A PopulationBased Case-Control Study. Sci Rep. 2016;6:23079.

6. Sonpavde G, Pond GR, Armstrong AJ, Clarke SJ, Vardy JL, Templeton AJ, et al. Prognostic impact of the neutrophil-toIymphocyte ratio in men with metastatic castration-resistant prostate cancer. Clin Genitourin Cancer. 2014;12:317-24.

7. Nanki $Y$, Chiyoda T, Kataoka F, Nomura $H$, Nakadaira N, Iwasa $\mathrm{N}$, et al. Elevated preoperative neutrophil : lymphocyte ratio as a preoperative indicator of mature cystic teratoma with malignant transformation. J Obstet Gynaecol Res. 2017;43:744-8.

8. Ljungberg B, Albiges L, Abu-Ghanem Y, Bensalah K, Dabestani S, Fernández-Pello $S$, et al. European Association of Urology Guidelines on Renal Cell Carcinoma: The 2019 Update. Eur Urol. 2019;75:799-810.

9. Albers P, Albrecht W, Algaba F, Bokemeyer C, CohnCedermark G, Fizazi K, et al. European Association of Urology. Guidelines on Testicular Cancer: 2015 Update. Eur Urol. 2015;68:1054-68.

10. Fankhauser CD, Sander S, Roth L, Gross 0, Eberli D, Sulser $\mathrm{T}$, et al. Systemic inflammatory markers have independent prognostic value in patients with metastatic testicular germ cell tumours undergoing first-line chemotherapy. $\mathrm{Br} J$ Cancer. 2018;118:825-30. 
11. Moore MM, Chua W, Charles KA, Clarke SJ. Inflammation and cancer: causes and consequences. Clin Pharmacol Ther. 2010;87:504-8.

12. Keizman D, Ish-Shalom M, Huang P, Eisenberger MA, Pili $\mathrm{R}$, Hammers $\mathrm{H}$, et al. The association of pre-treatment neutrophil to lymphocyte ratio with response rate, progression free survival and overall survival of patients treated with sunitinib for metastatic renal cell carcinoma. Eur J Cancer. 2012;48:202-8.

13. Dalpiaz O, Ehrlich GC, Mannweiler S, Hernández JM, Gerger A, Stojakovic T, et al. Validation of pretreatment neutrophil-lymphocyte ratio as a prognostic factor in a European cohort of patients with upper tract urothelial carcinoma. BJU Int. 2014;114:334-9.

14. Krane LS, Richards KA, Kader AK, Davis R, Balaji KC, Hemal AK. Preoperative neutrophil/lymphocyte ratio predicts overall survival and extravesical disease in patients undergoing radical cystectomy. J Endourol. 2013;27:1046-50.

15. Arda E, Yuksel I, Cakiroglu B, Akdeniz E, Cilesiz N. Valuation of Neutrophil/Lymphocyte Ratio in Renal Cell Carcinoma Grading and Progression. Cureus. 2018;10:e2051.
16. Viers BR, Thompson RH, Lohse CM, Cheville JC, Leibovich $\mathrm{BC}$, Boorjian SA, et al. Pre-treatment neutrophil-tolymphocyte ratio predicts tumor pathology in newly diagnosed renal tumors. World J Urol. 2016;34:1693-9.

17. Jankovich M, Jankovichova T, Ondrus D, Breza J. Neutrophilto-lymphocyte ratio as a predictor of preoperative tumor staging in testicular germ cell tumors. Bratisl Lek Listy. 2017;118:510-12.

18. Bolat D, Aydoğdu Ö, Polat S, Yarımoğlu S, Bozkurt İH, Yonguç T, et al. Predictive value of preoperative neutrophilto-lymphocyte ratio on the prognosis of germ cell testicular tumors. Turk J Urol. 2017;43:55-61.

Correspondence address: Ersan Arda, MD Department of Urology Trakya University School of Medicine Kocasinan Mah, Karabicak Apt., 1, 22030, Edirne, Turkey Telephone: +90 532 320-4814 E-mail: ersanarda@gmail.com 